REVIEW

This paper is dedicated to the $70^{\text {th }}$ anniversary of the founding of Physiologia Bohemoslovaca (currently Physiological Research)

\title{
Molecular Basis of the Effect of Atorvastatin Pre-treatment on Stem Cell Therapy in Chronic Ischemic Diseases - Critical Limb Ischemia
}

\author{
Adriana ADAMIČKOVÁ ${ }^{1}$, Andrea GAŽOVÁ ${ }^{2}$, Matúš ADAMIČKA ${ }^{3}$, Nikola \\ CHOMANIČOVÁ ${ }^{4}$, Simona VALAŠKOVÁ ${ }^{4}$, Zdenko ČERVENÁK ${ }^{1}$, Barbara ŠALINGOVÁ ${ }^{1}$, \\ Ján KYSELOVIČ ${ }^{1}$
}

${ }^{1} 5^{\text {th }}$ Department of Internal Medicine, Faculty of Medicine, Comenius University Bratislava, Slovakia, ${ }^{2}$ Institute of Pharmacology and Clinical Pharmacology, Faculty of Medicine, Comenius University Bratislava, Slovakia, ${ }^{3}$ Institute of Medical Biology, Genetics and Clinical Genetics, Faculty of Medicine, Comenius University Bratislava, Slovakia, ${ }^{4}$ Department of Pharmacology and Toxicology, Faculty of Pharmacy, Comenius University Bratislava, Slovakia

Received May 3, 2021

Accepted July 21, 2021

\begin{abstract}
Summary
Autologous stem cell therapy is the most promising alternative treatment in patients with chronic ischemic diseases, including ischemic heart disease and critical limb ischemia, which are characterized by poor prognosis related to serious impair of quality of life, high risk of cardiovascular events and mortality rates. However, one of the most serious shortcomings of stem cell transplantation are low survival after transplantation to the site of injury, as large number of stem cells are lost within 24 hours after delivery. Multiple studies suggest that combination of lipid-lowering drugs, statins, and stem cell transplantation might improve therapeutic efficacy in regenerative medicine. Statins are inhibitors of HMG-CoA reductase and belong to recommended therapy in all patients suffering from critical limb ischemia. Statins possess non-lipid effects which involve improvement of endothelial function, decrease of vascular inflammation and oxidative stress, anti-cancer and stem cell modulation capacities. These non-lipid effects are explained by inhibition of mevalonate synthesis via blocking isoprenoid intermediates synthesis, such as farnesylpyrophospate and geranylgeranylpyrophospate and result in modulation of the PI3K/Akt pathway. Moreover, statin-mediated microRNA regulation may contribute to the pleiotropic functions. MicroRNA interplay in gene regulatory network of IGF/Akt pathway may be of special significance for the treatment of critical limb ischemia.
\end{abstract}

We assume further studies are needed for detailed analysis of statin interactions with microRNA at the molecular level and their link to PI3K/Akt and IGF/Akt pathway in stem cells, which are currently the most promising treatment strategy used in chronic ischemic diseases.

\section{Key words}

Atorvastatin - Chronic ischemic diseases - Mesenchymal stem cells • microRNA

\section{Corresponding author}

A. Gažová, Faculty of Medicine, Comenius University, Špitálska 24, 81372 Bratislava, Slovak Republic.

E-mail: andrea.gazova@fmed.uniba.sk

\section{Stem cells and chronic ischemic diseases}

Ischemia or ischaemia is defined as an inadequate blood supply to a local area following blockage of the blood vessels, resulting in oxygen shortage. Chronic ischemic diseases include ischemic heart disease caused by coronary artery narrowing and critical limb ischemia (CLI). CLI is the most advanced stage of peripheral artery disease (PAD), defined by chronic ischemic rest pain, ischemic ulcerations, or 
ischemic gangrene as a result of compromised blood flow to the affected extremity. Approximately $40 \%$ of patients with CLI are ineligible for surgical or endovascular revascularization (no-option CLI patients) with 1-year mortality rate from $10 \%$ to $40 \%$ and $25 \% 1$-year amputation rate (Becker et al. 2011, Hassanshahi et al. 2019). Chronic ischemic diseases are characterized by macrovascular alterations accompanied by microvascular abnormalities, involving endothelial dysfunction mediated by inflammation, oxidative stress and ischemia (Vemulapalli et al. 2015). Despite the modern development of therapeutic techniques and methods, the treatment of no-option CLI patients is still very limited, among which stem cell transplantation appears to be one of the most promising alternative option. Stem cells are a class of undifferentiated cells with unique self-renewal capacity and the ability to differentiate into various cell types (Hassanshahi et al. 2019).

Several studies showed stem cell therapies in the treatment of no-option CLI patients reduce the rate of major amputations and pain and improve walk distance, perfusion and transcutaneous oxygen pressure (Compagna et al. 2015). A major shortcoming of the treatment is poor survival of transplanted bone marrow derived mesenchymal stem cells. Most mesenchymal stem cells (MSCs) are lost within 24 hours after cell-based treatment and only $15 \%$ of them are able to survive for 3 months. Therefore, protection of the implanted cells from acute death in ischemic injury is of major importance for clinical applications. Multiple studies reported that combination of lipid-lowering drugs, statins, recommended in prevention of coronary heart disease, with stem cell transplantation might improve therapeutic efficacy in regenerative medicine (Gorabi et al. 2020).

\section{Actions of statin in treatment}

The 3-hydroxy-3-methylglutaryl coenzyme A (HMG-CoA) reductase inhibitors or statins are principal drugs used in primary and secondary prevention of coronary heart disease. They inhibit the HMG-CoA reductase activity, the limiting enzyme in cholesterol synthesis in liver. Moreover, clinical trials have shown that statins have additional cholesterol-independent effects which involve improvement of endothelial function, decrease of vascular inflammation and oxidative stress, anti-cancer and stem cell modulation capacities (Xu et al. 2013). These non-lipid effects could be mediated by inhibition of mevalonate synthesis via blocking isoprenoid intermediates synthesis, such as farnesylpyrophospate and geranylgeranylpyrophospate. Isoprenoid intermediates serve as important posttranslational lipid attachments for intracellular signalling molecules such as the Rho GTPases (Rikitake and Liao 2005).

For clinical application were tested nine statins, which differ in their tissue permeability and metabolism. Lipophilic statins, like atorvastatin are widely distributed by passive diffusion to different tissues and cell types, including MSCs. In vivo, atorvastatin is metabolized by cytochrome $\mathrm{P} 4503 \mathrm{~A} 4$ to ortho and para hydroxyl derivatives, with approximately $70 \%$ of the circulating inhibitory activity attributed to the biologically active metabolites (Lennernas 2003). Cytochrome P450 expression occurs mainly in hepatocyte, and in addition its presence was also show in MSC isolated from bone marrow cells (Chiang et al. 2014). Therefore, we suggest that the effect of atorvastatin on the outcome of stem cell therapy is mediated by the molecular effect of atorvastatin on the population of MSCs present in mononuclear bone marrow derived cells.

According to European Society of Cardiology guidelines on the diagnosis and treatment of PAD statins belong to the recommended therapy for all patients with PAD. It was shown that statins cause reductions in all-cause mortality and cardiovascular events (Aboyans et al. 2017). The resulting improvement in therapeutic outcomes of regenerative medicine suggests benefit from combination of statin therapy and stem cell transplantation. The use of statin in combination with MSCs in the context of cellular therapy appears promising in also pre-clinical studies. Some pre-clinical studies combined statin therapy with cell transplantation using MSC or endothelial progenitor cells (EPCs). The study of Park et al. focused on the effect of statin therapy and MSC infusion in hindlimb ischemia in mice model. It reported improved outcomes, involving greater incorporation of transplanted cells into the size of injury, improved perfusion in affected limb and decreased apoptosis in ischemic muscle (Park et al. 2016). Additionally, different analysis evaluated results from pre-clinical studies involving animals with acute myocardial infarction treated with MSCs or atorvastatin and MSCs together. They found atorvastatin exerts protective effects on the myocardium undergoing infarction and reperfusion injury in connection with MSCs transplantation (Dai et al. 2015). Clinical studies also analyzed statin therapy impact on $\mathrm{CAD}$, using atorvastatin or rosuvastatin. They reported an increase in circulating EPCs levels after 5 days of statin therapy and greater 
numbers of colony-forming units after 6 months of treatment. They confirmed a reduction in wound infections, reduction in incidence of atrial fibrillation or other complications after following cardiac surgery (Park et al. 2016).

\section{Molecular basis of statins effects}

According to current knowledge, statins could affect MSC fate by several signalling pathways. They could influence MSCs differentiation, proliferation, angiogenic potential, survival, migration and homing capacities (Zhang et al. 2018). The main effect of statins is mediated by reduction in an early step of cholesterol synthesis, thus also inhibit the synthesis of isoprenoids such as farnesylpyrophoshate and geranylgeranylpyrophosphate. They are essential for posttranslational lipid attachments of intracellular signalling molecules like Rho GTPases family. GTPases function is regulated by their membrane localization, prenylation and posttranslational modification, which is impaired by statins. It affects Rho GTPases stability and activity, and is responsible for regulation cytoskeleton organization, cell adhesion, migration, and others. HMG-CoA inhibitors prevent endothelial dysfunction by RhoA inhibition, which is crucial for stabilization of mRNA endothelial NO synthase, and results in endothelial-dependent relaxation. Furthermore, RhoA and Rho-kinases inhibition increases mRNA endothelial NO synthase expression and activation and causes endothelialdependent relaxation. Moreover, statins maintain NO availability by reducing its degradation by free radical molecules. Rho-kinases also inhibit serine/threonine kinase Akt phosphorylation and its activity, which is reversed by statins. Thereafter Akt can phosphorylate endothelial NO synthase on serine 1179 and enhances its ability to generate NO (Gelosa et al. 2007). Through these statin effects on isoprenoid intermediates, we suggest that atorvastatin affects MSCs mainly through the phosphatidyl inositol 3-kinase (PI3K)/Akt signalling pathway (Fig. 1).

Well described statin mediated action is the increase of vascular endothelial growth factor (VEGF) expression, crucial for angiogenesis process. VEGF binds to tyrosine kinase receptor located on cell membrane and activate PI3K/Akt pathway. As a result, Akt phosphorylation modulates diverse cell processes including MSC differentiation into EPCs and activates signalling pathways involved in vasculogenesis. Multiple studies reported that besides VEGF statins (simvastatin, atorvastatin, rosuvastatin) also enhance the expression of several other growth factors, including basic fibroblast growth factor (bFGF), insulin-like growth factor (IGF-1) and hepatocyte growth factor (HGF) (Gorabi et al. 2020).

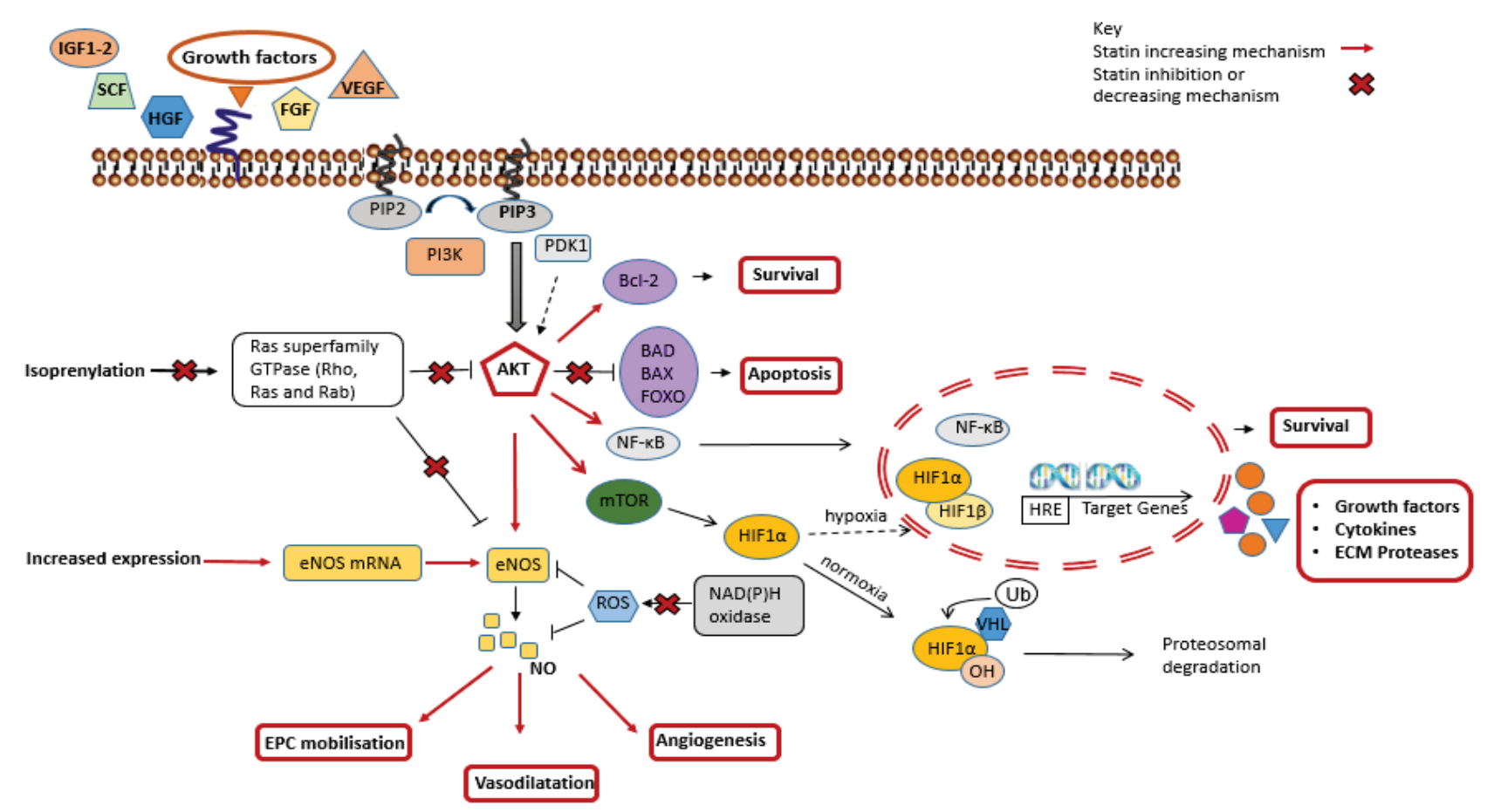

Fig. 1. Schematic representation of possible atorvastatin effects in PI3K/Akt pathway (modified Samakova et al. 2019). FGF, fibroblast growth factor; HGF, hepatocyte growth factor; HRE, hormone response element; IGF, insulin-like growth factor; PDK1, phospoinositidedepedent protein kinase-1; PI3K, phosphatidylinositol 3-kinase; PIP2, phosphatidylinositol-4,5-bisphosphate; PIP3, phosphatidylinositol3,4,5-bisphosphate; SCF, stem cell factor; VEGF, vascular endothelial growth factor. 
On the other hand, it has been reported that the concentrations of VEGF and hypoxia inducible factor (HIF) may be related to process like myocardial remodelling and angiogenesis. HIF is a transcription factor responding to the reduction or hypoxia in the cell environment. Activation of HIF-1 signalling cascade mediates the effects of hypoxia on the cells and allows the cells to differentiate continuously and promote the formation of blood vessels. VEGF is the main downstream target gene of HIF-1 $\alpha$, able to promote neovascularization and adaptation of cells to hypoxic environment. Study performed by Dulak and Józkowicz (2005) adds more to the understanding of the diverse effect of statins in ischemia processes. They studied the effect of atorvastatin combined with conventional treatment drugs for acute myocardial infarction on rats. The results showed that the concentration of HIF-1 and VEGF in the serum of rats with acute myocardial infarction were significantly higher than that of normal rats, suggesting their involvement in the occurrence of myocardial infarctions. By comparison of HIF-1 and VEGF levels in the routine therapy group and study group with atorvastatin showed higher concentration of HIF-1 and VEGF levels in the study group, suggesting that the combination of atorvastatin and routine therapy increased the concentrations of HIF and VEGF.

Interestingly, an important role in the physiology of MSCs is played by the IGF1 / IGF2 system, the association of which with statins as well as microRNAs is not fully elucidated. IGF-1 levels in adults are regulated by the bond of growth hormone to its hepatic receptor and stimulation of expression and release of IGF-1 peptide into circulation. At the molecular level, insulinlike growth factors (IGFs; IGF-1 and IGF-2) are two small polypeptides that regulate stem cell survival, selfrenewal and differentiation (Youssef et al. 2017). IGF-1 shares more than $60 \%$ sequence homology with IGF-2. They both act via the IGF-1 receptor (IGF-1R) which has 10-fold higher affinity to IGF-1, compared to IGF-2. The IGF-1R is a tetramer consisting of extracellular $2 \alpha$-chains and 2 transmembrane $\beta$-chains, including an intracellular tyrosine kinase, which mediates its biologic effects (Higashi et al. 2015). Randomized controlled trial by Bergen et al. evaluated the effect of atorvastatin treatment on IGF-1 and insulin-like growth factor binding protein levels (Bergen et al. 2016). Twenty patients with type 1 diabetes received placebo or $80 \mathrm{mg}$ atorvastatin for two months. They found atorvastatin treatment was associated with overall reduction in IGF-1 levels, which may indicate negative link to vascular health.

A few studies researched the effects of IGF-1 on MSCs differentiation potential, migratory capacity, and growth (Feng et al. 2014, Xinaris et al. 2013; Zhou et al. 2016). MSCs isolated from bone marrow express and secrete both IGF-1 and IGF-2 in vitro. Ectopic IGF-1 expression in MSCs was linked with proliferation and decrease of apoptosis (Hu et al. 2008). In contrast, IGF-2 appeared to be involved in promoting MSC pluripotency and self-renewal capacities. IGF-2 secreted by differentiated autologous fibroblast-like cells in response to basic FGF, was required for the maintenance of human embryonic stem cell pluripotency and self-renewal through IGF-1R signalling. Study with MSC isolated from human dental pulp confirmed that IGF-1R was required for MSC multipotency (Lee et al. 2016). The effect of statin, specifically simvastatin was investigated in relation to cell viability and IGF-1 signalling in differentiating $\mathrm{C} 2 \mathrm{C} 12$ mouse myoblast cells. Authors concluded that simvastatin decreases IGF-1 signalling via regulation of post-translational modification of IGF-1R beta chains (Ogura et al. 2007).

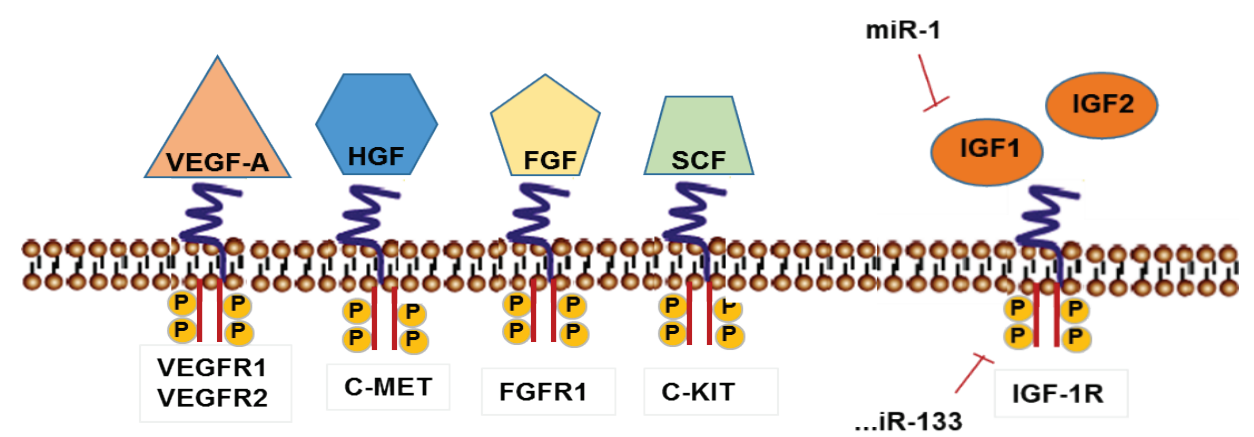

...iR-133
Fig. 2. Ligands and receptors involved in the activation of PI3K/Akt pathway. C-KIT, stem cell growth factor receptor; C-MET, hepatocyte growth factor receptor; FGF, fibroblast growth factor; FGFR1, fibroblast growth factor receptor 1; HGF, hepatocyte growth factor; IGF, insulin-like growth factor; IGF-1R, insulin-like growth factor 1 receptor; miR, microRNA; SCF, stem cell factor; VEGF-A, vascular endothelial growth factor A; VEGFR1/2, vascular endothelial growth factor receptor $1 / 2$. 


\section{Potential microRNA involvement in statins various effects}

Moreover IGF1 and IGF2 network is modulated by microRNA, sequence specific regulators of posttranscriptional gene expression (Fig. 2). Evidence available so far demonstrates various mechanism by which microRNAs down-regulate their target mRNA and revealed their essential roles. MicroRNAs profoundly impact gene regulatory networks, specifically IGF-1/IGF-2 signalling pathway in several ways ( $\mathrm{Hu}$ et al. 2013). One of the best studied processes involving microRNA effects on IGF1/Akt pathway is myogenesis. The expression levels of miR-1 and miR-133 increase during myogenesis and decrease in skeletal muscle hypertrophy. MiR-1 and miR-133 negatively regulate the IGF-1/Akt signalling pathway by targeting its positive regulators including IGF-1 and IGF-1R (Hitachi and Tsuchida 2014). It has been suggested that the beneficial effect of statins can be potentially explained by direct effect on selected mRNA levels, however another possible mechanism, microRNA post-transcriptional control of gene expression levels, needs to be elucidated.

\section{Conclusion}

Novel promising therapeutic strategies for the treatment of chronic ischemic diseases are constantly trying to increase the process of neoangiogenesis and neovascularization in the affected ischemic area. However, little is known about the benefit of long-term pharmacological pre-treatment of these patients and its effect on cell-based therapies. According to European Society of Cardiology guidelines on the diagnosis and treatment of PAD, statin belongs to recommended therapy in all patients (Aboyans et al. 2017). Inhibitors of HMC-CoA reductase have been widely used as hypolipidemic drugs for prevention of cardiovascular disease and have maintained a favorable safety profile for many years. It has been previously shown that statins can act through the PI3K/Akt pathway with protective effects for MSCs that could increase therapeutic outcome of stem cell transplantation in no-option CLI patients. In this review, we strongly suspect that statins affect PI3K/Akt pathway in stem cells directly through isoprenoid intermediates and indirectly through interactions with microRNA. However, further studies are needed for detailed analysis of statin interplay with microRNA at the molecular level and their link to PI3K/Akt and IGF/Akt pathway in stem cells, which are currently the most promising treatment strategy used in chronic ischemic diseases.

\section{Conflict of Interest}

There is no conflict of interest.

\section{Acknowledgements}

This work was supported by the VEGA 1/0378/21 grant.

\section{References}

ABOYANS V, RICCO J-B, BARTELINK M-LEL, BJÖRCK M, BRODMANN M, COHNERT T, COLLET J-P, CZERNY M, DE CARLO M, DEBUS S, ESPINOLA-KLEIN C, KAHAN T, KOWNATOR S, MAZZOLAI L, NAYLOR AR, ROFFI M, RÖTHER J, SPRYNGER M, TENDERA M, TEPE G, VENERMO M, VLACHOPOULOS C, DESORMAIS I, and DOCUMENT REVIEWERS: 2017 ESC Guidelines on the diagnosis and treatment of peripheral arterial diseases, in collaboration with the european society for vascular surgery (ESVS). Eur Heart J 2017. https://doi.org/10.5603/KP.2017.0216

BECKER F, ROBERT-EBADI H, RICCO J-B, SETACCI C, CAO P, DE DONATO G, ECKSTEIN H H, DE RANGO P, DIEHM N, SCHMIDLI J, TERAA M, MOLL F L, DICK F, DAVIES A H, LEPÄNTALO M, APELQVIST

J: Chapter I: Definitions, epidemiology, clinical presentation and prognosis. Eur J Vasc Endovasc Surg 42: 4-12, 2011. https://doi.org/10.1016/S1078-5884(11)60009-9

BERGEN K, BRISMAR K, TEHRANI S: High-dose atorvastatin is associated with lower IGF-1 levels in patients with type 1 diabetes. Growth Hormone \& IGF Res 29: 78-82, 2016. https://doi.org/10.1016/j.ghir.2016.06.001

COMPAGNA R, AMATO B, MASSA S, AMATO M, GRANDE R, BUTRICO L, DE FRANCISCIS S, SERRA R: Cell therapy in patients with critical limb ischemia. Stem Cells Int 2015: 1-13, 2015. https://doi.org/10.1155/2015/931420

DAI G, XU Q, LUO R, GAO J, CHEN H, DENG Y, LI Y, WANG Y, YUAN W, WU X: Atorvastatin treatment improves effects of implanted mesenchymal stem cells: meta-analysis of animal models with acute myocardial infarction. BMC Cardiovascular Disorders, vol.15: no.1: 2015. https://doi.org/10.1186/s12872-015-0162-6 
DULAK J, JÓZKOWICZ A. Anti-Angionenic and Anti-Inflammatory Effects of Statins: Relevance to Anti-cancer therapy. Curr Cancer Drug Targets 5 579-594, 2005. https://doi.org/10.2174/156800905774932824

FENG X, HUANG D, LU X, FENG G, XING J, LU J, XU K, XIA W, MENG Y, TAO T, LI T, GU Z: Insulin-like growth factor 1 can promote proliferation and osteogenic differentiation of human dental pulp stem cells via mTOR pathway. Development. Growth \& Differentiation 56: 615-624, 2014. https://doi.org/10.1111/dgd.12179

GELOSA P, CIMINO M, PIGNIERI A, TREMOLI E, GUERRINI U, SIRONI L: The role of HMG-CoA reductase inhibition in endothelial dysfunction and inflammation. Vasc Health Risk Management 3: 567-577, 2007.

GORABI AM, KIAIE N, PIRRO M, BIANCONI V, JAMIALAHMADI T, SAHEBKAR A: Effects of statins on the biological features of mesenchymal stem cells and therapeutic implications. Heart Failure Rev 2020. https://doi.org/10.1016/j.plipres.2020.101054

HASSANSHAHI M, KHABBAZI S, PEYMANFAR Y, HASSANSHAHI A, HOSSEINI-KHAH Z, SU Y, XIAN CJ: Critical limb ischemia: Current and novel therapeutic strategies. J Cell Physiol 234: 14445-14459, 2019. https://doi.org/10.1002/jcp.28141

HIGASHI Y, QUEVEDO HC, TIWARI S, SUKHANOV S, SHAI SY, ANWAR A, DELAFONTAINE P: The Interaction Between IGF-1, Atherosclerosis and Vascular Aging: 20, 2015.

HITACHI K, TSUCHIDA K: Role of microRNAs in skeletal muscle hypertrophy. Front Physiol: 4, 2014. https://doi.org/10.3389/fphys.2013.00408

HU C, WU Y, WAN Y, WANG Q, SONG J: Introduction of hIGF-1 Gene into Bone Marrow Stromal Cells and Its Effects on the Cell's Biological Behaviors. Cell Transplant 17: 1067-1081, 2008. https://doi.org/10.3727/096368908786991506

HU YK, WANG X, LI L, DU YH, YE HT, LI CY: MicroRNA-98 induces an Alzheimer's disease-like disturbance by targeting insulin-like growth factor 1. Neurosci Bulletin 29: 745-751, 2013. https://doi.org/10.1007/s12264$\underline{013-1348-5}$

CHIANG TS, YANG KC, WU YM, LAI HS, JIANG CC, CHIOU LL, LEE KL, HUANG GT, LEE HS: Higher expression of cytochrome P450 3A4 in human mesenchymal and adipose-derived stem cells than in dermal fibroblasts: With emphasis on the correlation with basal pregnane X receptor expression. Process Biochem 11: 1983-1989, 2014. https://doi.org/10.1016/j.procbio.2014.08.006

LEE DE, AYOUB N, AGRAWAL DK: Mesenchymal stem cells and cutaneous wound healing: novel methods to increase cell delivery and therapeutic efficacy. Stem Cell Res Therapy 7:37: 2016. https://doi.org/10.1186/s13287-016-0303-6

LENNERNAS H: Clinical pharmacokinetics of atorvastatin. Clin Pharmacokinet 42 (13):1141-1160, 2003. https://doi.org/10.2165/00003088-200342130-00005

OGURA T, TANAKA Y, NAKATA T, NAMIKAWA T, KATAOKA H, OHTSUBO Y: Simvastatin reduces insulinlike growth factor-1 signaling in differentiating c2c12 mouse myoblast cells in an hmg-coa reductase inhibition-independent manner. J Toxicol Sci 32: 57-67, 2007. https://doi.org/10.2131/jts.32.57

PARK A, BARRERA-RAMIREZ J, RANASINGHE I, PILON S, SY R, FERGUSSON D, ALLAN DS: Use of statins to augment progenitor cell function in preclinical and clinical studies of regenerative therapy: a systematic review. Stem Cell Rev Rep 12: 327-339, 2016. https://doi.org/10.1007/s12015-016-9647-7

RIKITAKE Y, LIAO JK: Rho GTPases, Statins, and Nitric Oxide. Circ Res 97: 1232-1235, 2005. https://doi.org/10.1161/01.RES.0000196564.18314.23

SAMAKOVA A, GAZOVA A, SABOVA N, VALASKOVA S, JURIKOVA M, KYSELOVIC J: The pi3k/Akt Pathway Is associated with angiogenesis, oxidative stress and survival of mesenchymal stem cells in pathophysiologic condition in ischemia. Physiol Res 68 (Suppl 2): S131-S138, 2019. https://doi.org/10.33549/physiolres.934345

VEMULAPALLI S, PATEL MR, JONES WS: Limb ischemia: cardiovascular diagnosis and management from head to toe. Curr Cardiol Rep 17: 611, 2015. https://doi.org/10.1007/s11886-015-0611-y 
XINARIS C, MORIGI M, BENEDETTI V, IMBERTI B, FABRICIO AS, SQUARCINA E, BENIGNI A, GAGLIARDINI E, REMUZZI G: A novel strategy to enhance mesenchymal stem cell migration capacity and promote tissue repair in an injury specific fashion. Cell Transplant 22: 423-436, 2013. https://doi.org/10.3727/096368912X653246

XU H, YANG YJ, YANG T, QIAN HY: Statins and stem cell modulation. Ageing Res Rev 12: 1-7, 2013. https://doi.org/10.1016/j.arr.2012.03.006

YOUSSEF A, ABOALOLA D, HAN VK: The roles of insulin-like growth factors in mesenchymal stem cell niche. Stem Cells Intern: 1-12, 2017. https://doi.org/10.1155/2017/9453108

ZHANG Z, YAO L, YANG J, WANG Z, DU G: PI3K/Akt and HIF-1 signaling pathway in hypoxia-ischemia (Review). Molecular Medicine Reports: 3547-3554, 2018. https://doi.org/10.3892/mmr.2018.9375

ZHOU Q, LI B, ZHAO J, PAN W, XU J, CHEN S: IGF-I induces adipose derived mesenchymal cell chondrogenic differentiation in vitro and enhances chondrogenesis in vivo. In Vitro Cellular \& Developmental Biology Animal 52: 356-364, 2016. https://doi.org/10.1007/s11626-015-9969-9 